\title{
Social Relationships and Trust
}

\author{
Christine Binzel* \\ Dietmar Fehr**
}

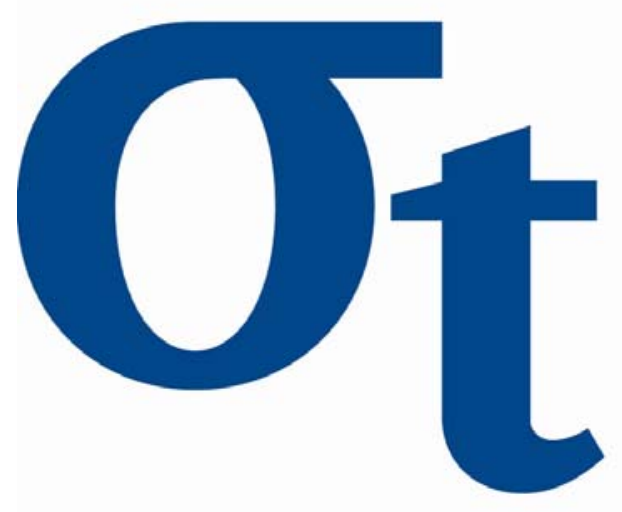

* DIW Berlin \& Humboldt University of Berlin

** Social Science Research Center Berlin (WZB)

This research was supported by the Deutsche Forschungsgemeinschaft through the SFB 649 "Economic Risk". 


\title{
Social Relationships and Trust*
}

\author{
Christine Binzel \\ DIW Berlin \& Humboldt University of Berlin \\ Dietmar Fehr \\ Social Science Research Center Berlin (WZB)
}

May 15, 2010

\begin{abstract}
While social relationships play an important role for individuals to cope with missing market institutions, they also limit individuals' range of trading partners. This paper aims at understanding the determinants of trust at various social distances when information asymmetries are present. Among participants from an informal housing area in Cairo we find that the increase in trust following a reduction in social distance comes from the fact that trustors are much more inclined to follow their beliefs when interacting with their friend. When interacting with an ex-ante unknown agent instead, the decision to trust is mainly driven by social preferences. Nevertheless, trustors underestimate their friend's intrinsic motivation to cooperate, leading to a loss in social welfare. We relate this to the agents' inability to signal their trustworthiness in an environment characterized by strong social norms.
\end{abstract}

Keywords: trust, hidden action, social distance, solidarity, reciprocity, economic development.

JEL Codes: C72, C93, D82, O12

* The paper has greatly benefited from discussions with Iris Bohnet, Tilman Brueck, Julian Jamison, Dean Karlan, Alexander Koch, Dorothea Kuebler, Jeff Nugent, Imran Rasul and Jennifer Rontganger. We also thank seminar participants at the DIW Berlin, Frankfurt University, Humboldt University of Berlin, Yale University and at the ESA European Meeting 2008, Econometric Society Summer Meeting 2009, VfS Annual Meeting 2009 and ERF Annual Conference 2009. We are indebted to the Participatory Development Program in Urban Areas of the German Technical Cooperation (GTZ) in Cairo, in particular to its staff at the local office in Manshiet Nasser and to our research assistants from Cairo University. Financial support from DIW Berlin, the German Research Foundation (DFG) through SFB 649 "Economic Risk" and the Economic Research Forum (ERF) is gratefully acknowledged.

Christine Binzel: German Institute for Economic Research (DIW Berlin), Department of International Economics, Mohrenstraße 58, 10117 Berlin, Germany. Phone +49-30-89789-408, E-mail: cbinzel@diw.de.

Dietmar Fehr: Social Science Research Center Berlin (WZB), Research Unit Market Behavior, Reichpietschufer 50, 10785 Berlin, Germany. Phone: +49-30-25491-404, E-mail: fehr@wzb.eu. 


\section{Introduction}

In developing countries formal (market) institutions are typically weak or non-existent (Cox and Fafchamps, 2008). It has been widely observed that transactions with strangers are rare, while most transactions take place within the social network. ${ }^{1}$ Social networks reduce transaction costs particularly through the provision of external enforcement mechanisms, such as monitoring and social sanctions (e.g. Coate and Ravallion, 1993; Platteau, 1994). What is then the value of trading with a socially close person relative to a stranger when external enforcement mechanisms are absent, and what are its determinants?

To address these questions, we conducted an experiment in an informal housing area in the Greater Cairo Region in Egypt whose residents strongly rely on their social relationships in their everyday lives (e.g. Singerman, 1995; Hoodfar, 1997). While these relationships enable them to cope with missing market institutions, they can also result in inefficiencies. A possible source of inefficiency originates from the limitation in an individual's range of trading partners and thus the fact that their social relationships determine, among other things, the extent to which goods are available, insurance can be provided, or loans can be obtained. At the same time, low trust toward non-group members, a common characteristic of strong social ties among kin and close friends (Ermisch and Gambetta, 2008; Alesina and Giuliano, 2009), can further limit the opportunities to obtain services and goods in the anonymous market. ${ }^{2}$ An important aspect in broadening the residents' access to, for instance, financial services is to understand the varied determinants of trust toward outsiders and toward socially close persons. In general it is assumed that beliefs are easier to change or influence than preferences, which are viewed as fixed over time and across environments. If differences in trust are mainly caused by greater unconditional kindness toward insiders, external actors will face difficulties in building up trust. If, instead, differences in trust are essentially driven by individuals' beliefs, promoting trust will boil down to signaling trustworthiness. An understanding of the influence of preferences and beliefs on individual decision making at various social distances can thus provide valuable insights for the design of policy interventions. Through our experimental design, we provide a framework to contribute precisely to this understanding.

In the experiment, we implemented a binary trust game using a within-subject design, i.e.

\footnotetext{
${ }^{1}$ Examples include mutual insurance (Fafchamps, 1992; Foster and Rosenzweig, 2001), the access to goods and services through reciprocal exchange (Kranton, 1996) and informal contract enforcement as exercised in rotating savings and credit associations (Fafchamps, 1996; Karlan, 2005; Karlan et al., 2009).

${ }^{2}$ More general, low trust toward strangers is typical for collectivist countries, including most developing countries, in which transactions mainly take place within groups and in which contract enforcement is informal (Greif, 1994).
} 
participants had to make two decisions out of which only one was implemented and paid. The only difference between the two decisions was the social distance toward the trading partner, i.e. participants interacted with a direct friend (familiar situation) and a randomly chosen stranger (unfamiliar situation). ${ }^{3}$ This allows us to investigate the determinants of trust and cooperation in different situations for the same person, and hence to automatically control for heterogeneity among participants.

We are especially interested in a situation in which monitoring or social sanctions are hardly possible, since this mirrors the transition from relationship-based to anonymous market transactions and constitutes a gateway for policy interventions. To capture the essence of such situations, we add a hidden action element to the trust game, i.e. the trustor (principal) cannot fully observe the action of the trustee (agent). ${ }^{4}$ If the principal places trust in the agent and the agent responds with cooperation, there is a small probability that the agent's cooperative effort is lost and the principal receives the betrayal payoff. Therefore, whenever the principal gets a low payoff she cannot be certain about the agent's decision irrespective of the social distance between the two.

This is not necessarily an uncommon situation for principals in a social network. For example, the effort of intermediaries who serve an important role for accessing goods and services in networks is often not observable (Singerman, 1995). A principal cannot be sure whether her middleman is occupied with helping others or whether he is willing to comply with her request. Also agents' social status and the multiple interdependencies between principals and agents within the network may impede the effectiveness of enforcement mechanisms. In such situations, transactions will depend on the principal's information or knowledge about the agent's type, i.e. whether the agent is trustworthy or not, as well as on his (social) preferences. Through the within-subject design we can control for the latter, in particular for unobserved individual differences, while the introduction of hidden action in the trust game ensures that reduced social distance works only through a reduction in information asymmetries and not through increased availability of extrinsic enforcement mechanisms.

The emergence of trust is often related to the ability of agents to communicate their trustworthiness (e.g. Arrow, 1972; Fukuyama, 1996), such that principals can distinguish between good

\footnotetext{
${ }^{3}$ In previous experimental studies, the term "social distance" has been mainly used to describe changes in the degree of anonymity either between participants and experimenter or between participants, for instance, by using double-blind procedures, by providing certain information about the other (e.g. gender or last name) or by letting participants meet before taking the decision. Hoffman, McCabe and Smith $(1996,1999)$; Bohnet and Frey (1999) are good examples for dictator games.

${ }^{4}$ Trust games conducted in developing countries have so far examined trust toward strangers mostly using the standard trust game design by Berg, Dickhaut and McCabe (1995).
} 
and bad types. However, this ability might be particularly hampered in environments with strong community norms, because they leave little leeway to incur an extra cost in order to signal trustworthiness. Also, if norms are internalized it is difficult to extract the motives behind benevolent behavior and thus to learn about the intrinsic motivation of others within the network. To account for norms of solidarity and reciprocity within the community, we conducted a series of dictator games utilizing the same within-subject design as in the trust game. We modify the dictator games by introducing role uncertainty. Thereby, we confront participants with the possibility of a positive or negative income shock. Participants in the role of the decision maker can respond to this (positive) shock by transferring a part of their endowment to the recipient. Exposing decision makers to recipients at different social distances (i.e. friend versus stranger) allows us to relate the value of social relationships to community norms. In order to distinguish between different motives for transfers, we implement two treatments: in the anonymous treatment, recipients do not learn whether the amount was transferred to them by their friend or by a stranger, whereas in the non-anonymous treatment, they receive this information at the end of the experiment. The anonymous dictator game hence provides a measure of participants' solidarity, while we measure participants' reciprocity in the non-anonymous dictator game due to possible future interaction. ${ }^{5}$

More recently, interest in the use of individuals' real-world social networks in experiments has increased. Most related to our study are the papers by D'Exelle and Riedl (2008), Leider et al. (2009), Goeree et al. (2010), and Brañas Garza et al. (forthcoming), which run dictator games to study prosocial giving in networks. Our study deviates from these studies in several respects.

First, our interest is not in studying prosocial giving, but in the effect of social distance on trust and its determinants. Thus, we are mainly interested in the behavior in the trust game and we complement this analysis with results from a series of dictator games to control for community norms and for participants' social preferences in the analysis. Second, we draw on a different, highly heterogeneous subject pool, residents of an informal housing area (Manshiet Nasser), who strongly depend on their social network for survival (e.g. Singerman, 1995; Hoodfar, 1997). Except for the study by D'Exelle and Riedl (2008) who collected their data from household heads in a village in Nicaragua all other studies were conducted among students or pupils in Europe and the US. Finally, we used a different procedure to access participants' real-world connections. We invited participants and required that they take part in our experiment together with a friend. This mutual

\footnotetext{
${ }^{5}$ This approach was pioneered by Leider et al. (2009). In contrast to our setup, Leider et al. (2009) do not introduce role uncertainty. They measure altruism in the anonymous treatment and future interaction effects in social networks in the non-anonymous treatment.
} 
agreement to participate in the experiment ensured a two-sided link between friends and at the same time determined the social distance of the relationship, which is usually defined as the path length between trading partners (e.g. Jackson, 2008). According to this definition we rely on relationships with the shortest possible path in a network, i.e. direct friends at social distance 1. Through our within-subject design we are able to compare behavior resulting from an interaction with a direct friend (familiar situation) with behavior in an unfamiliar situation in which the interaction takes place with a randomly chosen stranger, i.e. at infinite path length. In contrast, the aforementioned studies used network elicitation tools to obtain detailed information about the social network of the participants, also with the aim of analyzing additional questions, such as whether the content of the network (D'Exelle and Riedl, 2008) or participants' position within the network (Goeree et al., 2010) play a role. Leider et al. (2009) and Goeree et al. (2010) were further interested in dictator's behavioral pattern for several social distances, i.e. including indirect friends. The advantage of using network elicitation methods is that the experimenter can randomly draw one out of all direct friends. However, in all the studies mentioned, participants were limited to fellow pupils, students, and head of households, which might lead to an underestimation of the effect of social distance on behavior. In contrast, our study does not restrict the set of friends out of which invitees could choose, provided they were adults and not close family members. Somewhat similar is perhaps the approach used in Glaeser et al. (2000). They were interested in the methodological question of the predictability of trusting behavior by attitudinal survey questions in a standard trust experiment. They vary the social distance of participants by allowing them to self-select into pairs upon arrival and find that knowing each other longer results in slightly more trust and trustworthiness. ${ }^{6}$

We find that participants transfer a high share of their endowment to strangers (baseline solidarity) and a majority of them split the endowment equally in the one-way anonymous setup. This observed baseline solidarity varies little with individual characteristics suggesting a strong norm of solidarity within the community. Despite the high level of baseline solidarity, close social relationships are still of value: on average, transfers increase when the recipient is a friend. Transfers are also larger when the veil of anonymity is lifted, i.e. reciprocation in future interaction plays a role.

Participants' high level of solidarity is reflected by agents' behavior in the trust game where the main predicting variable for agents' probability to cooperate is their solidarity, regardless which

\footnotetext{
${ }^{6}$ They recruited students from an introductory economics class and allowed those who arrived together to play together, thereby raising the likelihood that participants know each other.
} 
situation they face. The results of the trust game reveal that a reduction in social distance is also associated with a significant increase in trust. The driving force behind this increase in trust comes from the fact that principals are much more inclined to follow their beliefs when interacting with their friend. In the unfamiliar situation, it seems that principals are not confident about their beliefs and, hence, their social preferences become more important. Nonetheless, in the familiar situation principals base their decision on wrong expectations since, on average, principals' friends are much more willing to cooperate than principals anticipate (72\% versus $40 \%$ ). Hence, they cannot fully reap the potential benefits from trust and cooperation. Estimation results suggest that principals do not incorporate their friend's baseline solidarity when forming their beliefs.

Low investment rates in the Arab region have been mostly attributed to the tribal nature of Arab societies that fosters trust only within limited boundaries and hampers it toward outsiders. Consequently, as Bohnet, Herrmann and Zeckhauser (forthcoming) demonstrate, participants from the Gulf are more betrayal averse than their Western counterparts and thus require higher probabilities of trustworthiness in order to enter a trust relationship. Against this background, our results are intriguing in that they suggest that strong social ties are not necessarily associated with high trust among insiders, either.

The rest of this paper is organized as follows. In Section 2, we provide some background information about the field setting and give an overview of the procedures along with a description of the setup of the games. Section 3 outlines the empirical strategy. Section 4 discusses the results from the dictator game. In section 5, we analyze the determinants of trust and cooperation and look more closely at individual friend pairs, in particular whether friends' expectations and behavior match. Section 6 discusses some policy implications and concludes.

\section{Research Design and Games}

\section{$2.1 \quad$ Background}

We conducted our study in Manshiet Nasser, one of the largest and oldest informal housing areas in Cairo. Manshiet Nasser is a squatter settlement built on government-owned land. Its location along the limestone cliffs of the Mokattam plateau and its difficult accessibility challenge any upgrading of basic infrastructure like water supply or sewage disposal. Living and environmental conditions are poor. Population estimates range from 420,000 to almost 1 million inhabitants. While estimates for Greater Cairo suggest a population density of around 40,069 per square kilometer (UNDP, 
2005), this figure is likely to be higher for Manshiet Nasser and other informal housing areas given the continued population growth and geographic limitations in expanding the area. ${ }^{7}$ The average household size is 6 persons and more than $30 \%$ of the families live in one single room (UN-HABITAT, 2003). In comparison to many other informal housing areas in developing countries, violent crime is a rare event. There is a low level of social engagement in Manshiet Nasser (UN-HABITAT, 2003). The few active non-governmental organizations (NGOs) typically have some religious - Muslim or Coptic - background. ${ }^{8}$ Other sources of activities are mostly informal savings associations, called gam'iyyaat in the Egyptian dialect. They are frequently used to meet financial needs, such as funeral or marriage costs (Singerman, 1995; Hoodfar, 1997).

Particularly in the informal housing areas, religion has come to play an important role in people's everyday lives. On the one hand, this is due to many residents originating from the more traditional, rural areas in Upper Egypt. On the other hand, and more importantly, the lack of formal institutions has opened up room for religious organizations to provide basic services to the people (Singerman, 1995). In recent years, for example, taking the veil has become a must for Muslim women while in the 1980s only very few women did so (Hoodfar, 1997). Gender roles are well-defined and compliance to Muslim norms and values is closely monitored (Bibars, 2001).

\subsection{Procedure}

Conducting a field experiment in a highly religious environment poses several challenges. The most important limitation was the fact that gambling is forbidden in Islam. We therefore refrained from additionally conducting a risk game in order to control for risk preferences in the trust game through an experiment (see section 3). We paid great attention to the choice of the recruiters, the instructor and the assistants (see below), as well as to the language used when announcing the experiment and during the experiment itself (see Appendix for the experimental procedures). In the timing and duration of the experimental sessions (workshops) we took further care that participants would not miss prayer times. ${ }^{9}$

We employed three local female assistants for the recruitment of participants. By using female recruiters we wanted to facilitate the recruitment of female participants. We provided recruiters only with some general information about the study. They were not aware of the purpose

\footnotetext{
${ }^{7}$ According to the 2006 Census, the population of Greater Cairo amounts to 18 million. Recent estimates suggest that more than $40 \%$ of the population of Greater Cairo live in informal housing areas.

${ }^{8}$ Estimates on the share of the Coptic population in Egypt range between $5 \%$ to $15 \%$.

${ }^{9}$ There is some flexibility on prayer times as long as a missed prayer is completed before the next one is scheduled.
} 
of the study nor did they know the game protocol or procedure. The recruiters invited pairs of friends, i.e. each invited participant (invitee) had to bring a friend. The invitee was told that participation in the workshop was only possible together with a friend. ${ }^{10}$ In total, 144 slum dwellers from all 9 districts of Manshiet Nasser participated in our study.

The participants are quite heterogeneous with respect to their socio-economic status, which is common for informal housing areas in Cairo, see Table 1. Educational attainment varies substantially among participants, ranging from illiterates (30\% of our sample) to university graduates $(10 \%)$. We also observe much heterogeneity related to age. Younger people in our sample typically have more education than older people, which reflects Egypt's efforts over the last decades to improve and expand the educational system. Only $9 \%$ of the illiterate participants are younger than 25. More than $60 \%$ of our sample spent some time of their life outside Manshiet Nasser. This fraction is higher for participants above the median age of 27 . The average household in our sample comprises of 6 members and has 3 rooms available. About $40 \%$ of the participants receive a regular monthly waged income with an average monthly income of 377 Egyptian pound (L.E.), which is equivalent to about 74 US\$. ${ }^{11}$ Despite this heterogeneity in terms of socio-economic background characteristics, friend pairs exhibit very similar characteristics with regard to age, schooling, employment status and wealth. All our friend pairs are same-sex pairs, which reflects the strong gender roles in Egypt. Many see each other on a daily basis and have known each other for many years.

We conducted five sessions with 24 to 30 participants within a week in May 2008. The sessions took place in the late afternoon at a cultural theater located in one of the central districts of Manshiet Nasser. It provided enough rooms and space to run the experiment, which is rare in Manshiet Nasser due to the lack of public infrastructure and space. The sessions were run by a female instructor, supported by a large group of assistants both male and female. ${ }^{12}$ The instructor and the assistants received extensive instructions and training before the experiment.

Upon arrival, participants could only register together with a friend. After the registration, they received a folder that contained three large envelopes with the material for the three tasks and the questionnaire as well as 5 L.E. as a show-up fee for arriving on time. The show-up fee was announced beforehand by the recruiters and had the purpose of strengthening our credibility. Participants were not allowed to open the folder. Invitees and their friends were then seated

\footnotetext{
${ }^{10}$ The only restriction was that we did not allow direct family members and minors to participate.

${ }^{11}$ At the time of the study, the exchange rate was about 1 Egyptian pound (L.E.) for 0.19 US dollar.

${ }^{12}$ We also employed several Coptic assistants.
} 
Table 1: Participants' Characteristics.

\begin{tabular}{lccccc}
\hline \hline Variable & N & Mean & Std. Dev. & Min & Max \\
\hline Female & 144 & $53 \%$ & & & \\
Muslim & 144 & $94 \%$ & & & \\
Born in Manshiet Nasser & 144 & $39 \%$ & & & \\
\hline Age & 144 & 30 & 11 & 17 & 64 \\
Years of schooling & 144 & 9 & 6 & 0 & 16 \\
Illiteracy & 144 & $31 \%$ & & & \\
Innumeracy & 144 & $12 \%$ & & & \\
\hline Ever-married & 144 & $53 \%$ & & & \\
Nr of children & 64 & 3 & 2 & 1 & 8 \\
Nr of siblings & 144 & 5 & 2 & 0 & 10 \\
Nr of persons per household & 144 & 6 & 2 & 1 & 11 \\
Rooms per household & 144 & 3 & 1 & 1 & 6 \\
\hline Volunteer in NGO & 144 & $29 \%$ & & & \\
Wage income (in L.E.) & 59 & 377 & 263 & 70 & 1690 \\
\hline
\end{tabular}

at spaced intervals in the front and, respectively, in the back of a large room to prevent any communication among friends. After a short introduction we required participants to give their consent for the experiment and the survey.

Explaining the games to participants with different levels of education poses a challenge and is time consuming. We addressed this challenge in several ways. The instructor read out aloud the instructions to ensure that every participant was given the same information and to minimize any educational advantage. Additionally, we illustrated the games on charts and demonstrated the procedure in front of the participants. Relevant parts were repeatedly explained by the instructor. Moreover, participants only learned about a game before they actually played it. This made it easier for participants to understand the games and also ensured that participants could not condition their behavior on subsequent tasks. There was no feedback about outcomes between the different games. After explaining a game, the instructor went through several examples. We did not allow any questions in public, but all participants could ask questions in private before playing a game. For the decisions, a participant and a research assistant went to a predetermined place outside the large room. If necessary, the research assistant explained the game once more or answered questions. The participants made their decisions in private and handed the envelope with the decision over to the assistant. Afterwards, participants were accompanied to their seat where they waited for further instructions. During this time, participants were monitored by two assistants to prevent any interaction among them. 
Each session started with the trust game followed by the two dictator games, a summingup and an interview-based questionnaire. The questionnaire contained questions on socio-economic characteristics, such as sex, age, education, employment status, and household assets, as well as questions on social and risk preferences and on characteristics of their relationship to the friend with whom they participated in the workshop. When questions referred to a scale, the interviewers showed smilies assigned to the upper and lower bound and, where applicable, to the mid point with the aim of helping the less educated participants. All decisions were performed with coded envelopes. During the entire experiment there was no interaction between participants and us. We did not change the order of the trust game and the dictator game because it involved more effort to explain the trust game and we wanted the participants' concentrated attention. However, we did change the order of the dictator games and decisions. On average, participants earned a total of 34 L.E. (approx. 6.5 US\$ at the time of the experiment) which is twice a worker's daily wage.

\subsection{Trust Game}

We used a binary trust game with hidden action as depicted in Figure 1 (see also Charness and Dufwenberg, 2006). The principal can either trust or distrust her agent. If she trusts, the agent can either betray or cooperate. In the latter case, there is a small chance (one-sixth) that the cooperative effort is lost for the principal. Applying backward induction and assuming selfish and risk-neutral participants, the "distrust" strategy with the sure outcome is the dominant strategy (although it is Pareto-inferior) since the principal would expect the agent to maximize his payoff by choosing the betray option. On the other hand, if a sufficient level of trust exists between participants, they will choose the (trust, cooperate) strategy. This should be the case despite the small chance of a low outcome for the principal. First of all, the expected payoff of the principal (assuming risk-neutrality) for this strategy is $202 / 3 \mathrm{~L}$.E. which is strongly preferable to the distrust strategy where the principal would receive only 10 L.E. Furthermore, we have chosen payoffs so that the joint payoff in case of bad luck is still greater than the joint payoff in the distrust case (24 L.E. versus 20 L.E.). So, provided both participants trust each other and given the trust game is played in a non-anonymous setup, pairs could afterwards just split the 24 L.E. so that each of them would be better off than if the principal had chosen to distrust in the first place. What this trust game nicely captures is the fact that economic exchanges often involve some moral hazard. If the principal receives only 4 L.E., it is impossible for her to find out whether the agent betrayed her or not, even if the agent is the principal's friend. 


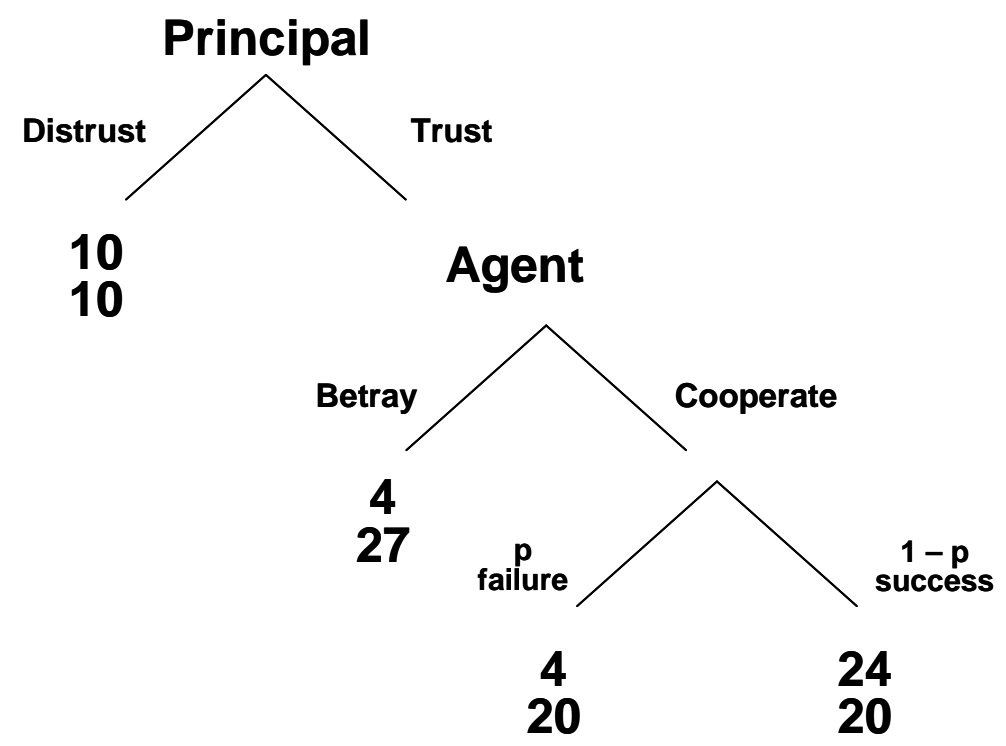

Figure 1: One-shot Binary Trust Game with Hidden Action for Agents (Payoffs in L.E., Egyptian Pound.)

In the beginning of each session a coin was tossed to determine whether invitees or their friends played the trust game as a principal. Since we expected a low level of trust, we implemented the strategy method for agents. We thus obtain an observation for every agent. To determine the success or failure in case of cooperation, the assistant drew one of six numbered cards after the agent made her decisions. A success was determined by card numbers 2, 3, 4, 5 or 6 and a failure by card number 1. Each principal and each agent played the game twice, once in the familiar situation interacting with a friend and once in an unfamiliar situation interacting with some other randomly chosen person ("stranger") among the other group (invitees or friends). ${ }^{13}$ We explained to participants at length that only one decision would determine their income and that the decision would be randomly selected in public at the end of the session. Both decisions were made in a non-anonymous setting, but we revealed the identities only ex-post. This means that participants learned at the end of the session with whom they had played the game. After making their decisions, participants were asked about their expectations about others' behavior for both decisions.

\subsection{Dictator Game}

In the second and third part of the experiment, participants played a dictator game. We modified the dictator games by introducing role uncertainty. This uncertainty resembles a positive income

\footnotetext{
${ }^{13}$ We varied the order of the decisions between sessions.
} 
shock for a decision maker and negative income shock for a recipient, respectively. Transfers can thus be interpreted as a mutual insurance against this shock, measuring an individual's solidarity toward other community members, rather than an individual's altruism (see also Coate and Ravallion, 1993). In each part a decision maker received two envelopes with 20 L.E. For the first decision, she had the possibility to allocate some or all of the 20 L.E. to her friend, and for the second, to a stranger. ${ }^{14}$ The dictator games in the two parts differed with respect to the anonymity of the decision maker. In the non-anonymous treatment (DGNA) the recipient learned ex-post the identity of the decision maker, while in the anonymous treatment (DGA) she did not. After the DGNA, we additionally asked decision makers why they had chosen that particular amount and what amount they would expect from their friend and, respectively, from some other person. Due to the role uncertainty each participant played the role of the decision maker and the role of the recipient. Thus, we had 144 decision makers, each making two decisions in the DGNA and two in the DGA. We paid participants either for their role as a decision maker or as a recipient and only for one decision per treatment (friend or stranger). We determined the role and the relevant decision for each treatment before the game was played but we revealed it only at the end of the session. To ensure anonymity in the DGA treatment, we determined only the role and not the payment-relevant decision. Analogous to Leider et al. (2009), in the anonymous dictator game we label the amount given to a stranger as "baseline solidarity" and the amount given to their friend "directed solidarity". ${ }^{15}$ In the non-anonymous dictator game, we measure reciprocity due to the possibility of future interaction and enforcement.

\section{Empirical Strategy}

We now outline our empirical strategy to explore the determinants of trust and cooperation. Utilizing our within-subject design, we are particularly interested in whether the role of participants' preferences and beliefs in economic exchanges changes following a reduction in the social distance between them and their trading partners. ${ }^{16}$ Following Coleman (1990) we adopt a behavioral definition of trust. Hence, the essence of trust is that a principal places something valuable at the

\footnotetext{
${ }^{14} \mathrm{As}$ in the trust game, we varied the order of the decisions between sessions.

${ }^{15}$ Leider et al. (2010) refer to the amount a decision maker gives to a nameless person as "baseline altruism" and the additional amount given to a friend as "direct altruism", thereby assuming that these amounts are additively separable. In order to allow for the possibility that these amounts are partial substitutes, we label the entire amount given to the friend as directed solidarity.

${ }^{16}$ Naef et al. (2009) show that differences in preferences and beliefs can explain most of the trust gap between the US and Germany. Note that they draw on a between-subject design.
} 
disposal of the agent with the belief that the other will not misuse it. ${ }^{17}$ Given this behavioral definition of trust and given that we measure trust through an experiment, participants' social and risk preferences should not affect beliefs about others' trustworthiness but should directly affect trust behavior (Fehr, 2009). We estimate the following binary choice models for principals' propensity to trust and, respectively, for agents' propensity to cooperate:

$$
\begin{gathered}
\text { Trust }_{i}=\beta_{1} \text { Exp }_{i}+\beta_{2} \text { SocPref }_{i}+\beta_{3} \text { RiskPref }_{i}+\beta_{4} \text { Net }_{i}+\beta_{5} \text { Friendship }_{i j}+\beta_{6} X_{i}+\epsilon_{i} \\
\text { Cooperate }_{i}=\beta_{1} \text { SocPref }_{i}+\beta_{2} \text { RiskPref }_{i}+\beta_{3} \text { Net }_{i}+\beta_{4} \text { Friendship }_{i j}+\beta_{5} X_{i}+\epsilon_{i}
\end{gathered}
$$

where Exp refers to principal $i$ 's expectation that the agent - her friend $j$ or some stranger will choose to cooperate, i.e., to reward her trust. SocPref encompasses measures for social, other-regarding preferences and RiskPref is an indicator for risk preferences. Net stands for characteristics of the principal's (general) social network while Friendship captures variables describing the relationship to her friend $j$. Finally, $X$ represents individual characteristics, such as sex, age and years of schooling. ${ }^{18}$

To capture social preferences we include the transfer to a stranger and to the friend in the anonymous dictator game, i.e. baseline and directed solidarity. We complement this measure with a dummy variable indicating whether the participant volunteers for a non-profit organization, i.e. a measure of altruism, and the frequency of lending money to friends (never, once or several times per year, or once a month or more). We anticipate observing a positive relationship between each of these variables and both trust and cooperation (e.g. Castillo and Carter, 2002; Ashraf, Bohnet and Piankov, 2006).

In order to measure risk we have to rely on attitudinal questions that were asked in the post-experimental questionnaire. Ideally, we would have liked to elicit risk attitudes through actual behavior in a risk game (see e.g. Schechter, 2007; Bohnet, Herrmann and Zeckhauser, forthcoming). We abstained from doing so since such a game could be associated with gambling, which is strictly forbidden in Islam (see section 2). We asked participants about their risk attitudes in general as well as with respect to financial aspects and to people. ${ }^{19}$ Admittedly, such risk measures might

\footnotetext{
${ }^{17}$ Alternatively, a purely belief-based trust definition would define trust as an expectation about trustworthiness and would not require a trusting act, i.e. placing something valuable at others' disposal.

${ }^{18}$ Note that the binary choice model for agents' decision to cooperate does not include expectations since we applied the strategy method.

${ }^{19}$ The questions are taken from the German Socio-Economic Panel (GSOEP). Participants were asked to answer the following questions on an 11-point scale they were shown by the assistant: "How do you see yourself: Are you generally a person who is fully prepared to take risks or do you try to avoid taking risks?" as well as "People can
} 
perform poorly in this context as it requires some level of abstraction and the level of education of our participants was low. Nevertheless, it should give us at least a proxy of the risk attitudes of our participants. ${ }^{20}$ The literature provides mixed evidence about the influence of risk attitudes on trust behavior (see e.g. Eckel and Wilson, 2004; Karlan, 2005; Schechter, 2007; Houser, Schunk and Winter, forthcoming). For instance, Schechter (2007) finds a positive impact of risk on trusting behavior for rural villagers in Paraguay whereas Houser, Schunk and Winter (forthcoming) find that risk preferences, albeit explaining behavior in a risk game, have no explanatory power in the trust game. We also control for risk preferences in agents' decision to cooperate because of the chance move following cooperation. Agents who are very risk averse might try to avoid being confronted with the chance move and are therefore more likely to choose "betray".

Network statistics provide information about an individual's wider social network irrespective of a particular relationship (see also Glaeser et al., 2000; Karlan et al., 2009). We include the number of close friends besides family members and a dummy if the first two sources of borrowing money are family members and close friends. We assume that having few close friends and borrowing money primarily from friends and relatives are proxies for strong social ties. Following Ermisch and Gambetta (2008) and Alesina and Giuliano (2009), we expect that this is associated with a lower probability to trust strangers and a higher probability to trust friends. Similarly, strong social ties are likely to be associated with lower reciprocity toward strangers compared to friends. Additionally, we control for the participant's perception of her immediate neighborhood as a proxy for her embeddedness in the community (see also Alesina and La Ferrara, 2002). If participants perceive their neighbors as strangers they are more dependent on their network, fostering trust toward friends and diluting trust toward strangers. ${ }^{21}$

While all friends brought to the workshop are direct friends with two-sided links, we nevertheless want to assess possible differences in the quality of the relationship. For instance, it is possible that some participants are forced into a particular relationship because of existing group ties, geographic proximity or someone's value for accessing certain goods and services. If this is

behave differently in different situations. How would you rate your willingness to take risks in the following areas: (a) financial matters, (b) faith in other people". The 11-point scale ranges from trying to avoid risks ("0") to fully prepared to take risks ("10").

${ }^{20}$ Dohmen et al. (2005) have shown for a representative German sample that these risk questions predict actual risk behavior in experiments pretty well. Recently, Hardeweg, Menkhoff and Waibel (2009) validated the same risk questions with a representative subsample of a panel survey in rural Thailand. They show that the general risk question as used in this study correlates with behavior in a risk game. However, the relationship is stronger for better educated participants.

${ }^{21}$ Alesina and La Ferrara (2002) suggest that trust is influenced by how long an individual has lived in a community. We therefore alternatively used a dummy for being born in Manshiet Nasser. However, it does not significantly affect trust and cooperation. 
Table 2: Summary Statistics for the Dictator Game.

\begin{tabular}{|c|c|c|c|}
\hline & & \multicolumn{2}{|c|}{ treatments } \\
\hline & & anonymous (DGA) & non-anonymous (DGNA) \\
\hline \multirow{2}{*}{ social distance } & stranger & $7.29(3.55)$ & $7.90(3.10)$ \\
\hline & friend & $8.85(3.12)$ & $9.21(2.60)$ \\
\hline
\end{tabular}

the case, we would observe different behavior depending on the authenticity of the relationship. We include the following two dummy variables: whether friends meet daily and whether they have known each other for more than four years. The two measures give us a proxy for the intrinsic value of the relationship, information exchange and for learning about each other's type (Homans, 1950; Marmaros and Sacerdote, 2006). Hence, we expect higher trust and cooperation among friends with more frequent interactions and long-term relationships. Both intuitions also have a long-standing game theoretical foundation (e.g. Kreps et al., 1982; Kranton, 1996; Karlan et al., 2009).

\section{The Value of Relationships at Different Social Distances}

In this section, we take a look at how social distance affects transfers in the dictator games as we incorporate behavior revealed in the dictator games as possible determinants of trust and cooperation in the empirical analysis of the trust game. The dictator games also provide us with a measure of the strength of social norms in the community.

We have a total of 144 participants who made four allocation decisions each. The results are shown in Table 2. On average, decision makers allocate 7.29 L.E. (36\%) of the available 20 L.E. to a socially distant recipient (stranger) in the anonymous treatment. If decision makers can direct the transfer toward a socially close person, i.e. a friend, transfers increase on average to 8.85 L.E. (44\%). The loss of anonymity for decision makers leads to a further increase in transfers. If the recipient is a stranger, decision makers allocate on average 7.90 L.E. (40\%) to the recipient. If instead the recipient is a socially close person, she receives on average 9.21 L.E. (46\%). Compared to the DGA, the social distance effect in the DGNA is slightly smaller ( $17 \%$ versus $22 \%$ ). The higher transfers in response to a reduction in social distance and to the loss of anonymity are each 
statistically significant at the $99 \%$ and the $95 \%$ level, respectively. ${ }^{22}$ Note that the social distance effect and the non-anonymity effect are substitutes (compare with Leider et al., 2010): the higher the amount allocated to a friend relative to a stranger under anonymity, the less the decision maker gives extra to her friend under non-anonymity. ${ }^{23}$ The variance of the amount given also changes with respect to social distance and anonymity. It is smallest for friends in the NA treatment and is statistically different from the variance in the anonymous treatment (variance ratio test; $p=0.03$ ) as well as from the variance of the amount given to a stranger in the NA treatment (variance ratio test; $p=0.04)$.

The observed high shares of giving are similar to results for dictator games conducted in other developing countries. Cardenas and Carpenter (2008) provide an extensive overview of the experimental evidence. They report an average allocation to strangers of about $38 \%$ in experiments using a non-student subject pool. This is also consistent with evidence in the development economics (Fafchamps, 1992) and in the anthropological literature (Sahlins, 1972; Singerman, 1995; Hoodfar, 1997) on strong norms of solidarity and ("balanced") reciprocity among the poor as a form of mutual insurance. These norms are explained by people's high exposure, or vulnerability, to a variety of shocks, such as economic, environmental, and health shocks, against which they often cannot formally insure and typically have limited resources to cope with (Fafchamps, 1999).

The high level of solidarity is the main difference to studies in Western cultures and also explains the larger difference between transfers to friends and strangers in these studies, see e.g. Leider et al. (2009), Goeree et al. (2010), or Brañas Garza et al. (forthcoming). These studies find that decision makers increase their giving between $36 \%$ to $52 \%$ if the recipient is a direct friend instead of a stranger, even under anonymity. Similar to our study, D'Exelle and Riedl (2008) observe a comparatively low increase of giving to direct friends of $18 \%$ among household heads in rural Nicaragua. Additional evidence for strong social norms comes from participants' expectations. In the DGNA, participants expect to receive 6.67 L.E. $(\mathrm{sd}=2.99, \mathrm{~N}=144)$ from a stranger, which is about 1 L.E. less than they themselves give on average. From a socially close person they expect to receive 9.26 L.E. $(\mathrm{sd}=2.66, \mathrm{~N}=144)$, slightly more than their average transfer.

In order to analyze how baseline solidarity is associated with transfers to the friend, we run

\footnotetext{
${ }^{22}$ In both, DGA and DGNA, running t-tests yield a $p<0.01$ for the reduction in social distance. For the loss of anonymity for strangers and friends the t-tests yield a $p<0.025$.

${ }^{23}$ This can be demonstrated by running the following regression: $N A E$ ffect ${ }_{i}=\beta_{1} S D E f f e c t_{i}+\beta_{2} X_{i}+\epsilon_{i}$ where $\triangle N A E f_{f e c t}{ }_{i}$ is the difference between transfers to the friend in the anonymous and in the non-anonymous treatment and $\triangle S D E$ ffect $_{i}$ is the difference between transfers to a friend and a stranger in the DGA. The coefficient $\beta_{1}$ is smaller than one and statistically significant.
} 
Table 3: Determinants of the Transfer to a Friend in the Anonymous and Non-Anonymous Dictator Game.

\begin{tabular}{|c|c|c|c|c|}
\hline & \multicolumn{4}{|c|}{ Decision makers' transfer to friend } \\
\hline & \multicolumn{2}{|c|}{ DGA } & \multicolumn{2}{|c|}{ DGNA } \\
\hline & $(1)$ & $(2)$ & $(3)$ & $(4)$ \\
\hline Baseline solidarity & $\begin{array}{l}0.570 * * * \\
(0.092)\end{array}$ & $\begin{array}{l}0.548 * * * \\
(0.100)\end{array}$ & $\begin{array}{l}0.246 * * * \\
(0.084)\end{array}$ & $\begin{array}{l}0.239 * * * \\
(0.089)\end{array}$ \\
\hline$\Delta$ Baseline solidarity & & $\begin{array}{r}-0.074 \\
(0.069)\end{array}$ & & $\begin{array}{r}-0.020 \\
(0.040)\end{array}$ \\
\hline Decision maker's expectation & & & $\begin{array}{l}0.517 * * * \\
(0.121)\end{array}$ & $\begin{array}{l}0.522 * * * \\
(0.126)\end{array}$ \\
\hline Age & $\begin{array}{c}0.024 \\
(0.021)\end{array}$ & $\begin{array}{c}0.024 \\
(0.024)\end{array}$ & $\begin{array}{c}0.032 * * \\
(0.016)\end{array}$ & $\begin{array}{r}0.031 * \\
(0.017)\end{array}$ \\
\hline$\Delta$ Age & & $\begin{array}{c}0.006 \\
(0.030)\end{array}$ & & $\begin{array}{c}0.015 \\
(0.024)\end{array}$ \\
\hline Female & $\begin{array}{c}0.249 \\
(0.412)\end{array}$ & $\begin{array}{c}0.289 \\
(0.417)\end{array}$ & $\begin{array}{r}-0.065 \\
(0.298)\end{array}$ & $\begin{array}{r}-0.101 \\
(0.257)\end{array}$ \\
\hline Years of schooling & $\begin{array}{c}0.054 \\
(0.081)\end{array}$ & $\begin{array}{c}0.048 \\
(0.079)\end{array}$ & $\begin{array}{c}0.067 \\
(0.041)\end{array}$ & $\begin{array}{r}0.075 * \\
(0.042)\end{array}$ \\
\hline$\Delta$ Years of schooling & & $\begin{array}{c}0.034 \\
(0.039)\end{array}$ & & $\begin{array}{c}0.038 \\
(0.030)\end{array}$ \\
\hline Wealth & $\begin{array}{r}-0.213 \\
(0.417)\end{array}$ & $\begin{array}{r}-0.228 \\
(0.447)\end{array}$ & $\begin{array}{r}-0.288 \\
(0.198)\end{array}$ & $\begin{array}{c}-0.251 \\
(0.233)\end{array}$ \\
\hline$\Delta$ Wealth & & $\begin{array}{c}0.359 \\
(0.535)\end{array}$ & & $\begin{array}{r}-0.166 \\
(0.337)\end{array}$ \\
\hline $\mathrm{N}$ & 144 & 144 & 144 & 144 \\
\hline $\mathrm{R}^{2}$ & 0.43 & 0.44 & 0.57 & 0.57 \\
\hline
\end{tabular}

$* \mathrm{p}<0.10,{ }^{* *} \mathrm{p}<0.05, * * * \mathrm{p}<0.01$

OLS regressions with standard errors reported in parentheses. In all specifications, standard errors account for clustering on the decision maker and recipient level (twoway clustering). DGA refers to the anonymous dictator game, DGNA to the nonanonymous dictator game. Wealth is an index calculated from participants' household assets using factor analysis. $\Delta$ refers to the absolute difference between decision maker and friend characteristics of the respective variable. 
standard OLS regressions for both treatments, DGA and DGNA. ${ }^{24}$ We use the following model:

$$
\text { Giving }_{i}=\beta_{1} \text { Base }_{i}+\beta_{2} E X P_{i}+\beta_{3} X_{i}+\epsilon_{i}
$$

where Giving is either decision maker $i$ 's transfer to the friend in DGA or DGNA. Base is the decision maker's baseline solidarity and $X$ represents individual characteristics such as age, sex and years of schooling. For the NA treatment, we additionally include the decision maker's expectation about his friend's level of giving in the DGNA, EXP. In a second specification, we also control for differences between the characteristics of decision makers and their friends. Since a decision maker $i$ is asked to make a transfer to her friend $j$ and, vice versa, her friend $j$ is asked to make a transfer to $i, E\left[\epsilon_{i}, \epsilon_{j}\right] \neq 0$, that is the error terms of each friend pairing are correlated. In order to correct standard errors, we apply a two-way clustering as proposed by Miller, Cameron and Gelbach (2009). The results are displayed in columns (1) to (4) in Table 3.

In both treatments, the transfer of decision makers to their friend is largely determined by their baseline solidarity. A one-unit increase in their baseline solidarity is associated with a 0.57 unit increase in the transfer in the DGA (column 1). In the DGNA, the coefficient is smaller $(0.25$ and 0.24 , respectively) as the decision makers' transfer is strongly determined by their expectations about their friends' norm of reciprocity. As mentioned earlier, given the comparatively low level of baseline solidarity, studies on social networks in Western societies found considerably larger increases (e.g. Leider et al., 2009). A larger difference in baseline solidarity between the decision maker and her friend reduces directed giving. The coefficient is, however, not significant. Individual characteristics of the decision maker and her friend have no influence on transfers. The fact that individual characteristics have little effect on the allocation decision in the dictator game has also been observed by other studies (D'Exelle and Riedl, 2008; Goeree et al., 2010).

In sum, we observe a high level of solidarity among our participants. Nonetheless, social distance significantly affects transfers emphasizing the value of close social relationships. 


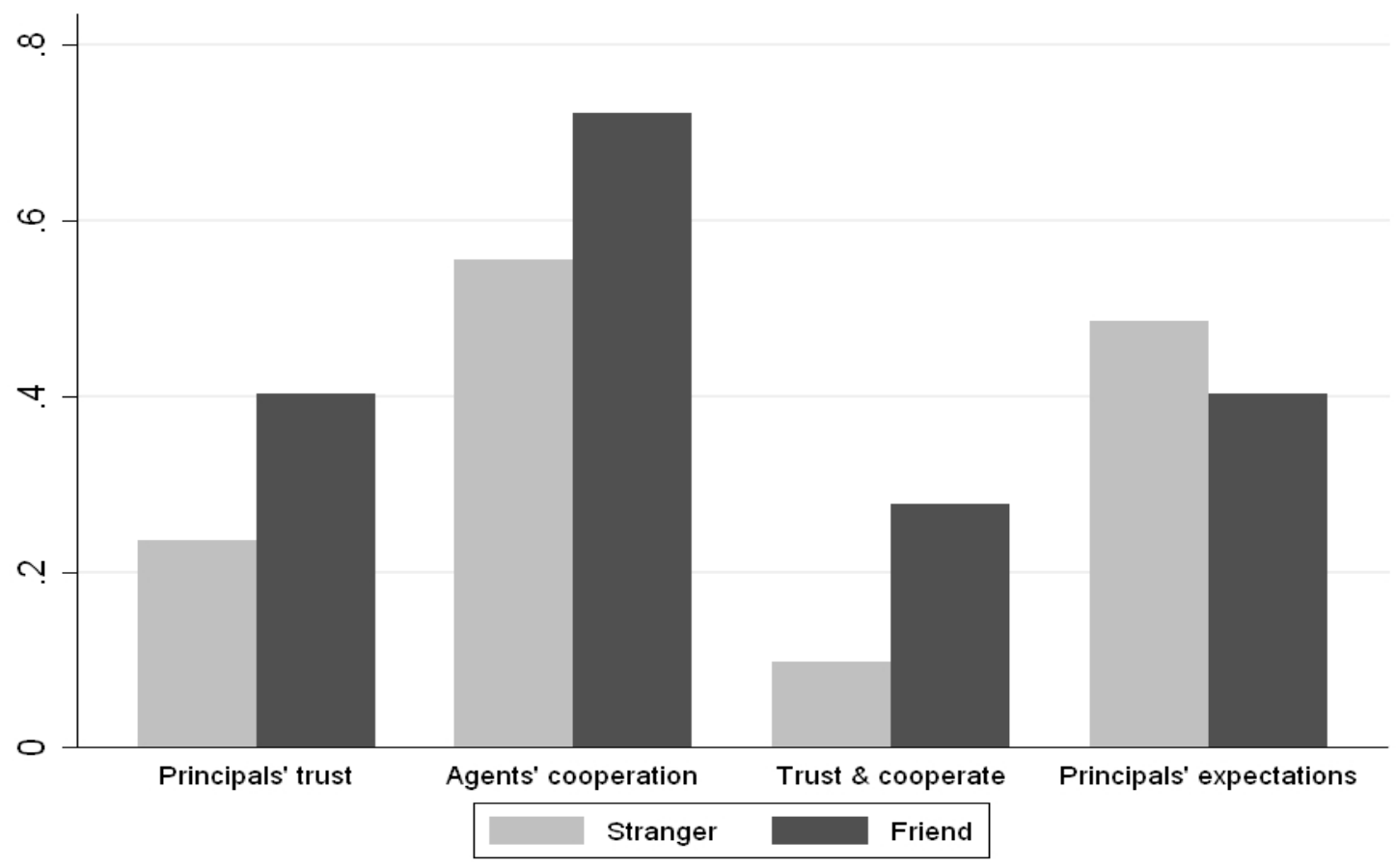

Figure 2: The Effect of Social Distance on Behavior in the Trust Game.

\section{How a Reduction in Social Distance Affects Trust and Cooper- ation}

\subsection{Determinants of Trust and Cooperation}

Figure 2 presents the aggregate results of the trust game. Only 17 out of 72 principals (24\%) opted for trust when confronted with a stranger. The trust rate increases substantially to $40 \%$ (29 out of 72) when confronted with a socially close person. Agents, on the other hand, seem reluctant to cheat even though principals cannot observe their actions. Nevertheless, agents are also sensitive toward decreased social distance. The cooperation rate of agents increases from $55 \%$ when confronted with a stranger to $72 \%$ when interacting with a socially close person. ${ }^{25}$ Reduced social distance also leads to efficiency gains. In the unfamiliar situation, only 7 out of 72 pairs $(10 \%)$ succeed in implementing the (trust, cooperate) outcome compared to 20 pairs (28\%) in the

\footnotetext{
${ }^{24}$ Our results are very similar when we run the regressions using a standard Tobit model.

${ }^{25}$ Cardenas and Carpenter (2008) provide a survey of trust experiments in developing countries. Compared to students in industrialized countries, trust toward strangers is typically low in developing countries, a finding that is overall in line with the literature on strong social ties. It also seems that trustworthiness is higher for non-student populations. Note that all surveyed experiments used a standard trust game and a direct comparison of the results is not warranted.
} 
familiar situation. Interestingly, we find a rather wide gap between trust and cooperation: Whereas on average only $40 \%$ of the principals opt for "trust", $72 \%$ of all agents opt for "cooperate". We come back to this in section 5.2 .

Estimation results for principals' propensity to trust and agents' propensity to cooperate are presented in Tables 4 and 5 (for a detailed explanation of the underlying empirical models see section 3). Using the fact that we have two decisions for each principal and each agent - i.e., one for each pairing - we display marginal effects from estimating random effects probit models with robust standard errors in the first four columns. The dummy variable "paired with friend" refers to the familiar situation, i.e. it measures the effect of a decrease in social distance on an individual's decision. Note that expectations as well as the amount given in the DGA differ by pairing; all other variables do not change. In the last three columns we report marginal effects from separate regressions for strangers and friends.

The estimates from the first four models in Table 4 provide a clear picture. Principals trust socially close persons significantly more than strangers and this is mainly driven by their expectations. In the third and fourth model, we additionally control for risk and social preferences as well as for individual characteristics. ${ }^{26}$ We find some evidence that social preferences matter. Principals who show more solidarity in the dictator game tend to place more trust in agents, but this is not statistically significant. The frequency of lending money and volunteering significantly increase the likelihood of trust. Risk preferences seem to have no impact. Alternative measures for risk, such as the responses given to the other two risk questions (see section 3) or a dummy for self-employment, do not change results.

The models in columns (5) and (6) show that expectations do not significantly affect principals' trust in strangers while they significantly and strongly affect trust in friends, i.e. principals who expect a cooperative behavior of their friend are $46 \%$ to $48 \%$ more likely to opt for trust. The results further suggest that the decision to trust a stranger is mainly influenced by social preferences. Both the frequency of lending money and volunteering significantly increase the probability that principals trust a stranger and the coefficients for baseline solidarity, volunteering and lending money are jointly significant. ${ }^{27}$ In the last column, we additionally control for differences in the type of relationship among our friend pairs. However, neither coefficient is statistically significant.

Overall it seems plausible that principals' social (and risk) preferences weigh more heavily

\footnotetext{
${ }^{26}$ Including additional variables to control for invitees and wealth levels do not change the results.

${ }^{27} \mathrm{~A}$ Wald test is significant at the 95 percent level. The same test is not significant for the friend pairing $(p>0.33)$.
} 
Table 4: Determinants of Principals' Behavior in the Trust Game.

\begin{tabular}{|c|c|c|c|c|c|c|c|}
\hline & $\begin{array}{c}\text { panel-I } \\
(1)\end{array}$ & $\begin{array}{c}\text { panel-II } \\
(2) \\
\end{array}$ & $\begin{array}{l}\text { Principal } \\
\text { panel-III } \\
(3) \\
\end{array}$ & $\begin{array}{l}\text { s' decision } \\
\text { panel-IV } \\
(4) \\
\end{array}$ & $\begin{array}{l}\text { to trust } \\
\text { stranger } \\
\quad(5)\end{array}$ & $\begin{array}{c}\text { friend-I } \\
(6)\end{array}$ & $\begin{array}{c}\text { friend-II } \\
(7) \\
\end{array}$ \\
\hline Paired with friend (d) & $\begin{array}{c}0.204 * * \\
(0.082)\end{array}$ & $\begin{array}{l}0.223 * * * \\
(0.083)\end{array}$ & $\begin{array}{l}0.215 * * \\
(0.085)\end{array}$ & $\begin{array}{l}0.214 * * \\
(0.085)\end{array}$ & & & \\
\hline Principal's expectations (d) & & $\begin{array}{l}0.273 * * * \\
(0.092)\end{array}$ & $\begin{array}{l}0.302 * * * \\
(0.093)\end{array}$ & $\begin{array}{l}0.301 * * * \\
(0.096)\end{array}$ & $\begin{array}{c}0.135 \\
(0.102)\end{array}$ & $\begin{array}{l}0.479 * * * \\
(0.113)\end{array}$ & $\begin{array}{l}0.462 * * * \\
(0.120)\end{array}$ \\
\hline (Baseline/directed) solidarity & & & $\begin{array}{c}0.009 \\
(0.015)\end{array}$ & $\begin{array}{c}0.009 \\
(0.015)\end{array}$ & $\begin{array}{c}0.001 \\
(0.014)\end{array}$ & $\begin{array}{c}0.011 \\
(0.019)\end{array}$ & $\begin{array}{c}0.011 \\
(0.020)\end{array}$ \\
\hline Volunteer $(\mathrm{d})$ & & & $\begin{array}{c}0.201 * \\
(0.120)\end{array}$ & $\begin{array}{l}0.264 * * \\
(0.133)\end{array}$ & $\begin{array}{c}0.199 * \\
(0.125)\end{array}$ & $\begin{array}{c}0.185 \\
(0.128)\end{array}$ & $\begin{array}{c}0.179 \\
(0.131)\end{array}$ \\
\hline Frequency of lending & & & $\begin{array}{c}0.118 * \\
(0.066)\end{array}$ & $\begin{array}{c}0.118 * \\
(0.069)\end{array}$ & $\begin{array}{l}0.172 * * \\
(0.071)\end{array}$ & $\begin{array}{c}0.031 \\
(0.084)\end{array}$ & $\begin{array}{c}0.027 \\
(0.086)\end{array}$ \\
\hline Risk preferences & & & $\begin{array}{c}-0.003 \\
(0.015)\end{array}$ & $\begin{array}{r}-0.002 \\
(0.015)\end{array}$ & $\begin{array}{c}-0.008 \\
(0.014)\end{array}$ & $\begin{array}{c}0.006 \\
(0.020)\end{array}$ & $\begin{array}{c}0.009 \\
(0.019)\end{array}$ \\
\hline Close friends $(\#)$ & & & & & $\begin{array}{c}-0.007 \\
(0.005)\end{array}$ & $\begin{array}{c}-0.011 \\
(0.007)\end{array}$ & $\begin{array}{c}-0.012 \\
(0.007)\end{array}$ \\
\hline Borrowing within network (d) & & & & & $\begin{array}{c}-0.068 \\
(0.109)\end{array}$ & $\begin{array}{c}0.111 \\
(0.145)\end{array}$ & $\begin{array}{c}0.125 \\
(0.139)\end{array}$ \\
\hline Neighbors like strangers (d) & & & & & $\begin{array}{r}-0.135 \\
(0.089)\end{array}$ & $\begin{array}{c}0.263 * \\
(0.144)\end{array}$ & $\begin{array}{r}0.269 * \\
(0.143)\end{array}$ \\
\hline Daily visits (d) & & & & & & & $\begin{array}{r}-0.079 \\
(0.143)\end{array}$ \\
\hline Long-term relation $(\mathrm{d})$ & & & & & & & $\begin{array}{c}-0.100 \\
(0.123)\end{array}$ \\
\hline Controls & No & No & No & Yes & No & No & No \\
\hline $\begin{array}{l}\mathrm{N} \\
\text { Pseudo } \mathrm{R}^{2}\end{array}$ & 144 & 144 & 144 & 144 & $\begin{array}{r}72 \\
0.15\end{array}$ & $\begin{array}{r}72 \\
0.21\end{array}$ & $\begin{array}{r}72 \\
0.22\end{array}$ \\
\hline
\end{tabular}

(d) marginals for discrete change of dummy variable from 0 to 1

$* \mathrm{p}<0.10, * * \mathrm{p}<0.05, * * * \mathrm{p}<0.01$

Marginal effects are reported with robust standard errors in parentheses from estimating random effects and simple probit models for the probability that the principal opts for trust. Frequency of lending money is a categorical variable (never, once/several times per year, or once per month or more). Risk refers to an 11-point scale ranging from trying to avoid risks ("0") to fully prepared to take risks ("10"). Controls include age, sex and years of schooling of individuals as well as dummies for household head and born in Manshiet Nasser. 
Table 5: Determinants of Agents' Behavior in the Trust Game.

\begin{tabular}{|c|c|c|c|c|c|c|c|}
\hline & \multicolumn{7}{|c|}{ Agents' decision to cooperate } \\
\hline & $\begin{array}{c}\text { panel-I } \\
(1)\end{array}$ & $\begin{array}{c}\text { panel-II } \\
(2)\end{array}$ & $\begin{array}{c}\text { panel-III } \\
(3) \\
\end{array}$ & $\begin{array}{c}\text { panel-IV } \\
(4)\end{array}$ & $\begin{array}{c}\text { stranger } \\
(5) \\
\end{array}$ & $\begin{array}{c}\text { friend-I } \\
(6)\end{array}$ & $\begin{array}{c}\text { friend-II } \\
\quad(7)\end{array}$ \\
\hline Paired with friend (d) & $\begin{array}{c}0.221 * * \\
(0.089)\end{array}$ & $\begin{array}{c}0.114 \\
(0.092)\end{array}$ & $\begin{array}{c}0.124 \\
(0.093)\end{array}$ & $\begin{array}{c}0.117 \\
(0.094)\end{array}$ & & & \\
\hline (Baseline/directed) solidarity & & $\begin{array}{l}0.061 * * * \\
(0.017)\end{array}$ & $\begin{array}{l}0.056 * * * \\
(0.018)\end{array}$ & $\begin{array}{l}0.054 * * * \\
(0.018)\end{array}$ & $\begin{array}{l}0.066 * * * \\
(0.019)\end{array}$ & $\begin{array}{l}0.067 * * * \\
(0.022)\end{array}$ & $\begin{array}{l}0.072 * * * \\
(0.022)\end{array}$ \\
\hline Volunteer $(\mathrm{d})$ & & & $\begin{array}{c}0.076 \\
(0.119)\end{array}$ & $\begin{array}{c}0.007 \\
(0.139)\end{array}$ & $\begin{array}{r}-0.067 \\
(0.140)\end{array}$ & $\begin{array}{c}0.142 \\
(0.090)\end{array}$ & $\begin{array}{c}0.169 * \\
(0.086)\end{array}$ \\
\hline Frequency of lending & & & $\begin{array}{c}0.008 \\
(0.070)\end{array}$ & $\begin{array}{c}0.038 \\
(0.073)\end{array}$ & $\begin{array}{r}-0.062 \\
(0.088)\end{array}$ & $\begin{array}{c}0.038 \\
(0.066)\end{array}$ & $\begin{array}{c}0.065 \\
(0.067)\end{array}$ \\
\hline Risk preferences & & & $\begin{array}{c}0.009 \\
(0.015)\end{array}$ & $\begin{array}{c}0.009 \\
(0.015)\end{array}$ & $\begin{array}{c}0.020 \\
(0.018)\end{array}$ & $\begin{array}{r}-0.008 \\
(0.015)\end{array}$ & $\begin{array}{r}-0.015 \\
(0.015)\end{array}$ \\
\hline Close friends $(\#)$ & & & & & $\begin{array}{r}-0.004 \\
(0.004)\end{array}$ & $\begin{array}{c}0.005 * \\
(0.003)\end{array}$ & $\begin{array}{c}0.004 * \\
(0.002)\end{array}$ \\
\hline Borrowing within network (d) & & & & & $\begin{array}{r}-0.128 \\
(0.127)\end{array}$ & $\begin{array}{c}0.161 \\
(0.112)\end{array}$ & $\begin{array}{c}0.098 \\
(0.112)\end{array}$ \\
\hline Neighbors like strangers (d) & & & & & $\begin{array}{c}0.251 * \\
(0.128)\end{array}$ & $\begin{array}{l}0.272 * * * \\
(0.088)\end{array}$ & $\begin{array}{l}0.285 * * * \\
(0.084)\end{array}$ \\
\hline Daily visits $(\mathrm{d})$ & & & & & & & $\begin{array}{l}0.228 * * \\
(0.113)\end{array}$ \\
\hline Long-term relation $(\mathrm{d})$ & & & & & & & $\begin{array}{c}0.111 \\
(0.105)\end{array}$ \\
\hline Controls & No & No & No & Yes & No & No & No \\
\hline $\begin{array}{l}\mathrm{N} \\
\text { Pseudo } \mathrm{R}^{2}\end{array}$ & 144 & 144 & 144 & 144 & 72 & $\begin{array}{r}72 \\
025\end{array}$ & $\begin{array}{r}72 \\
31\end{array}$ \\
\hline & & & & & 0.16 & 0.25 & 0.31 \\
\hline
\end{tabular}

(d) marginals for discrete change of dummy variable from 0 to 1

$* \mathrm{p}<0.10, * * \mathrm{p}<0.05, * * * \mathrm{p}<0.01$

Marginal effects are reported with robust standard errors in parentheses from estimating random effects and simple probit models for the probability that the agent opts for cooperate in the binary trust game. Frequency of lending money is a categorical variable (never, once/several times per year, or once per month or more). Risk refers to an 11-point scale ranging from trying to avoid risks ("0") to fully prepared to take risks ("10"). Controls include age, sex and years of schooling of individuals as well as dummies for household head and born in Manshiet Nasser. 
in the decision-making process when uncertainty about the agent's behavior becomes high, i.e. when principals face difficulties in forming expectations about the agent's behavior. A reduction in social distance between trading partners, on the other hand, leads to a reduction in information asymmetries and thus to higher trust.

The estimation results for modeling agents' decision to cooperate are shown in Table 5. Without controlling for other factors, the magnitude of the friend dummy is nearly the same as in Table 4 and significant. The second and third column suggest that cooperation is strongly correlated with solidarity, i.e. the amount given in the DGA. Each additional Egyptian pound given in the DGA increases the probability to opt for cooperate by about $6 \%$ on average. This is in line with other evidence, for example Castillo and Carter (2002) or Ashraf, Bohnet and Piankov (2006). Remember, however, that directed solidarity is significantly greater than baseline solidarity so that higher levels of cooperation in the friend pairing are reflected by the higher amount given to the friend relative to the stranger in the DGA. Other control variables, such as age and years of schooling, do not have any significant effect (column 4).

Looking at the results for the single regressions in the last three columns sheds more light on the determinants of different cooperation levels in the stranger and friend case. Cooperation in both the unfamiliar and the familiar situation is mainly driven by agents' solidarity. In the familiar situation, additional variables affect agents' probability to cooperate. In line with our hypothesis, strong social ties - proxied by the number of close friends - are associated with a higher probability to cooperate with the friend. Moreover, cooperation is more likely among friends who see each other daily.

\subsection{Determinants and Accuracy of Principals' Expectations}

The previous analysis suggests that trust between socially close persons is mainly driven by expectations. However, Figure 2 reveals two further interesting observations. First, on the aggregate level principals' expectations are not sensitive to a change in social distance. Principals expect on average a slightly less cooperative behavior from their friend than from a stranger (see Figure 2), albeit this difference is not statistically significant $\left(\chi_{(1)}^{2}=1.01, p=0.314\right)$. Second and relatedly, there is a large gap in the familiar situation between principals' expected cooperation level and agents' actual willingness to cooperate. While principals significantly best respond more to their expectations when confronted with a friend than with a stranger $\left(\chi_{(1)}^{2}=4.33, p=0.037\right)$, expectations are not more accurate in the familiar situation $\left(\chi_{(1)}^{2}=1.78, p=0.182\right)$. Both observations 
indicate that the potential gains from trade are not fully realized.

Subsequently, we first look at the determinants of principals correctly anticipating their friend's behavior. Note that this is independent of whether the friend cooperates or not since knowing the agent better may also result in expecting betrayal. For this, we regress the corresponding binary variable on a set of individual characteristics of the principal, on a dummy variable indicating whether the friend transferred a higher amount in the non-anonymous compared to the anonymous treatment and on variables describing the quality of the friendship between the two (for details about these variables see section 3). Columns (1) and (2) of Table 6 display the results. As a robustness check we alternatively considered cooperative behavior only, see column (3), but results hardly change. We find that women have more accurate expectations about their friend's behavior. This corresponds to the fact that women often organize and run informal savings groups called gam'iyyaat (Singerman, 1995), which requires a good assessment of people in order to select reliable and trustworthy members. It is also in line with empirical evidence from microfinance programs and informal savings groups that women exhibit higher repayment rates than men (Morduch, 1999; Anderson and Baland, 2002). Long-term relationships have a positive and significant effect on the accuracy of beliefs, too. This is consistent with economic models of social interaction. More interaction is associated with a greater flow of information and a smaller error in assessing the other. The accuracy of expectations is negatively affected if a friend displays a non-anonymity effect in the dictator game, i.e. that a decision maker gives more to a friend if transfers are observable (DGNA treatment). This suggests that principals have more difficulties in assessing the behavior of friends whose norm compliance is also motivated by extrinsic motivation.

High solidarity is associated with giving up a greater amount of money and thus this cost can serve as a signal for trustworthiness (e.g. Camerer, 1988). Hence, if agents were successful in signaling their trustworthiness, principals should - based also on our findings in the previous section - expect a higher willingness to cooperate from friends who show more solidarity. To test this claim, we additionally regress principals' expectations on a set of individual characteristics of both the principal and the friend, in particular we include the friend's directed solidarity, i.e. the amount the friend allocated to the principal in the anonymous dictator game. ${ }^{28}$ Regression results are presented in columns (4) and (5) in Table 6. They reveal that principals fail to incorporate their friend's directed solidarity.

\footnotetext{
${ }^{28}$ We also tested whether risk and social preferences affect expectations. We found no impact and, therefore, do not include them in the analysis. This is in line with Naef et al. (2009) and Fehr (2009).
} 
Table 6: Principals' Expectations in the Trust Game.

\begin{tabular}{|c|c|c|c|c|c|}
\hline & \multicolumn{5}{|c|}{ Principals' expectations } \\
\hline & \multicolumn{3}{|c|}{ accuracy } & \multicolumn{2}{|c|}{ determinants } \\
\hline & $(1)$ & $(2)$ & $(3)$ & 4 & $(5)$ \\
\hline Age & $\begin{array}{c}0.007 \\
(0.007)\end{array}$ & $\begin{array}{c}0.009 \\
(0.007)\end{array}$ & $\begin{array}{c}0.006 \\
(0.006)\end{array}$ & $\begin{array}{c}-0.003 \\
(0.007)\end{array}$ & $\begin{array}{c}-0.008 \\
(0.008)\end{array}$ \\
\hline Female (d) & $\begin{array}{l}0.311 * * * \\
(0.113)\end{array}$ & $\begin{array}{l}0.343 * * * \\
(0.122)\end{array}$ & $\begin{array}{l}0.333 * * * \\
(0.098)\end{array}$ & $\begin{array}{c}0.262 * * \\
(0.113)\end{array}$ & $\begin{array}{c}0.288 * * \\
(0.113)\end{array}$ \\
\hline Years of Schooling & $\begin{array}{c}0.003 \\
(0.014)\end{array}$ & $\begin{array}{c}0.000 \\
(0.015)\end{array}$ & $\begin{array}{c}0.007 \\
(0.011)\end{array}$ & $\begin{array}{c}-0.005 \\
(0.013)\end{array}$ & $\begin{array}{c}-0.020 \\
(0.017)\end{array}$ \\
\hline Born in Manshiet Nasser (d) & $\begin{array}{c}-0.192 \\
(0.131)\end{array}$ & $\begin{array}{c}-0.344 * * \\
(0.136)\end{array}$ & $\begin{array}{c}-0.292 * * * \\
(0.088)\end{array}$ & $\begin{array}{r}-0.127 \\
(0.125)\end{array}$ & $\begin{array}{r}-0.052 \\
(0.140)\end{array}$ \\
\hline Friend: higher transfer in DGNA (d) & & $\begin{array}{c}-0.345 * * * \\
(0.114)\end{array}$ & $\begin{array}{c}-0.239 * * * \\
(0.067)\end{array}$ & & \\
\hline Accuracy of beliefs in DGNA & & $\begin{array}{r}0.043 * \\
(0.025)\end{array}$ & $\begin{array}{l}0.040 * * \\
(0.019)\end{array}$ & & \\
\hline Daily visits (d) & & $\begin{array}{c}-0.017 \\
(0.143)\end{array}$ & $\begin{array}{c}0.009 \\
(0.103)\end{array}$ & & \\
\hline Long-term relation $(\mathrm{d})$ & & $\begin{array}{l}0.364 * * * \\
(0.138)\end{array}$ & $\begin{array}{c}0.218 * * \\
(0.109)\end{array}$ & & \\
\hline Friend: directed solidarity & & & & $\begin{array}{c}-0.025 \\
(0.020)\end{array}$ & $\begin{array}{r}-0.031 \\
(0.020)\end{array}$ \\
\hline Friend: volunteer (d) & & & & & $\begin{array}{c}0.267 * \\
(0.151)\end{array}$ \\
\hline Friend: frequency of lending & & & & & $\begin{array}{c}0.061 \\
(0.088)\end{array}$ \\
\hline Friend: risk preferences & & & & & $\begin{array}{c}0.018 \\
(0.019)\end{array}$ \\
\hline Friend: close friends $(\#)$ & & & & & $\begin{array}{c}-0.016 * * \\
(0.007)\end{array}$ \\
\hline Friend: borrowing within network (d) & & & & & $\begin{array}{r}-0.141 \\
(0.132)\end{array}$ \\
\hline Friend: neighbors like strangers (d) & & & & & $\begin{array}{c}0.283 * \\
(0.145)\end{array}$ \\
\hline $\mathrm{N}$ & 72 & 72 & 72 & 72 & 72 \\
\hline Pseudo $\mathrm{R}^{2}$ & 0.12 & 0.22 & 0.30 & 0.08 & 0.20 \\
\hline
\end{tabular}

(d) marginals for discrete change of dummy variable from 0 to 1

$* \mathrm{p}<0.10, * * \mathrm{p}<0.05, * * * \mathrm{p}<0.01$

Marginal effects are reported from estimating probit models on the probability that principals' expectations are correct and on the determinants of the probability that principals' expect cooperation. Columns (1) and (2) report results independent from whether the principal correctly anticipated cooperation or betray and column (3) reports results for correctly anticipating cooperation only. Variables are defined as before. "Higher transfer in DGNA" refers to the transfer made in the DGA. "Accuracy of beliefs in DGNA" refers to the absolute deviation between principals' expectation about the amount allocated to them by their friend in the DGNA and the actual amount given. Robust standard errors in parentheses. 
What can explain principals' ignorance of their friend's intrinsic motivation? Cooperative agents earned 20 L.E., which corresponds to one to two days' wages. Compared to this payoff, the additional gain from cheating (7 L.E.) was relatively small. This additional gain seems to have been less tempting for agents than assumed by principals and, consequently, principals might have underestimated their friend's intrinsic motivation to cooperate. ${ }^{29}$ In other words, principals neglected the additional costs for agents that arise with betrayal, i.e. the intrinsic cost of violating the norm of reciprocity and also the intrinsic cost of lying. ${ }^{30}$ These costs are possibly higher the more frequent the interaction between friends. Indeed, the fact that daily interaction leads to more cooperation could reflect a higher intrinsic motivation not to cheat (see column 7 in Table 5).

Furthermore, results from the dictator game revealed that a reduction in social distance has a positive and significant effect on transfers and thus that relationships are valuable. Against this background, it is all the more puzzling that principals were unable to anticipate agents' behavior, and that they failed to realize that agents' decision in the trust game is similar to the reciprocal exchange situation in the DGNA. ${ }^{31}$ The overall high solidarity and reciprocity among participants might, however, also dilute any signal from agents so that principals cannot effectively distinguish between good and bad types in their everyday life based on observed social preferences. The underlying problem is, it seems, that in committed relationships even selfish individuals cooperate: "Committed partners may often be assured of mutual cooperation, but this does not mean that they trust each others's goodwill" (Yamagishi and Yamagishi, 1994, p.135). If strong social norms are present in the network, there is little need to learn about the trading partners' type. Extracting this information in such an environment is also costly because there is not much room to obtain such information. The difficulty and disincentive to learn about the others' type in the network leads to the low level of trust when enforcement mechanisms are absent as in the trust game. The irony is that if principals expect their friend not to cooperate and thus abstain from a trusting decision they will in turn never learn about the trustworthiness or type of their friends, either.

\footnotetext{
${ }^{29} \mathrm{~A}$ similar finding is reported in Leider et al. (2010) where recipients show quite an accurate assessment of decision makers' giving across various social distances but systematically underestimate their baseline altruism.

${ }^{30}$ Anecdotal evidence and anthropological studies suggest considerable levels of mistrust even within the social (kin) network. Singerman (1995) reports about a business owner who employed his two younger brothers to run the shop. After a while, however, the owner realized that his brothers were taking out a greater share of the profits than agreed upon. Lacking the possibility to sanction their behavior, he found himself monitoring his brothers in the shop. Thus it might not be uncommon for principals to expect an agent, including a friend, to capitalize on a situation with hidden action. Relatedly, Barr, Dekker and Fafchamps (2008) and Barr and Genicot (2008) find that genetic relatedness does not necessarily support enforcement based on intrinsic motivation.

${ }^{31}$ As agents were asked to assume a trusting principal, they may have felt obliged to reciprocate trust with cooperate behavior. This would be consistent with a norm of "balanced reciprocity", which is a prevalent norm in this context as discussed earlier.
} 
However, we also provided evidence that long-term relationships alleviate the assessment of good and bad types. But, as with adapting preferences, this requires time.

\section{Conclusions}

In this paper, we study how the social distance between two trading partners influences their behavior in several exchange situations. The main insights from this paper are the following: First, although reduced social distance significantly increases giving in the anonymous and nonanonymous dictator game, the increase - compared to findings in developed countries (e.g. Leider et al., 2009) - is small relative to the amount given to a stranger. Interestingly, reciprocity toward friends is to a lesser extent associated with individuals' directed solidarity than with expectations about the reciprocal behavior of their friend.

Second, even though principals cannot draw on informal enforcement mechanisms when interacting with their friend, trust and cooperation among friends is higher than among strangers. Similar to the results for reciprocity, we find that the increase in trust is not driven by stronger social preferences toward friends but by expected returns. On the contrary, differences in cooperation levels toward friends and strangers can be fully explained by differences between agents' baseline and directed solidarity. Put differently, agents treat their decision problem similar to the one in the dictator game and, consequently, behave in a similar way. Principals' behavior, on the other hand, is neither related to their own level of solidarity, nor are expectations about their friend's behavior very accurate. Their expectations are too low relative to agents' cooperation levels, since they underestimate their friend's baseline solidarity. As a result, social welfare in the trust game is lost.

We explain this gap between overall trust and cooperation among friends by the little leeway strong social norms in these communities leave for agents to signal their trustworthiness. These strong social norms of solidarity and reciprocity prevail since it is also beneficial for selfish agents to comply with these norms given that formal market institutions are weak or non-existent. Complementary to this, principals find themselves in a situation with little control over their friend's decision due to the hidden action element in the trust game. They themselves cannot observe their friend's behavior nor can they draw on their social network. As a result, many principals wrongly refrain from trusting their friend.

Understanding the determinants of trust toward outsiders relative to socially close persons 
is important for decision makers in order to design successful policy interventions. The fact that strong social ties are associated with low trust toward strangers can create a challenging environment for policy makers, development agencies and NGO's previously unknown ('strange') to a community. From the viewpoint of the community, on the other hand, the implementation of any new development program is associated with various sources of uncertainties as agencies and their employees are not subject to the enforcement mechanisms and norms adhered to in the community. While our results indicate that strong norms within the community make signaling difficult among friends, there might be more scope for external actors, such as development agencies. Credibility seems crucial for trust building as well as true, measurable benefits. Participants in our experiment faced difficulties in assessing, or believing in, others' goodwill whereas in a quid pro quo exchange, they were willing to engage with a stranger and a friend in an almost equal manner. Thus, the fact that external actors often promise benefits without asking for anything in return may, while well-intended, by itself cause distrust or suspicion. Interestingly, there is evidence that many Islamic organizations in the informal housing areas which provide health care and other services do require something in return, even if in a more indirect manner through requiring women to conform to Muslim norms and values, e.g. by taking the veil (Bibars, 2001). While women may not be enthusiastic about this particular type of return, they may feel a sense of control about what is exchanged in the transaction and can weigh one against the other. 


\section{References}

Alesina, Alberto, and Eliana La Ferrara. 2002. "Who Trusts Others?" Journal of Public Economics, 85: 207-234.

Alesina, Alberto, and Paola Giuliano. 2009. "Family Ties and Political Participation." IZA Discussion Papers 4150.

Anderson, Siwan, and Jean-Marie Baland. 2002. "The Economics of Roscas and Intrahousehold Resource Allocation." Quarterly Journal of Economics, 117(3): 963-995.

Arrow, Kenneth J. 1972. "Gifts and Exchanges." Philosophy and Public Affairs, 1(4): 343-362.

Ashraf, Nava, Iris Bohnet, and Nikita Piankov. 2006. "Decomposing Trust and Trustworthiness." Experimental Economics, 9(3): 193-208.

Barr, Abigail, and Garance Genicot. 2008. "Risk Sharing, Commitment and Information: An Experimental Analysis." Journal of the European Economic Association, 6(6): 1151-1185.

Barr, Abigail, Marleen Dekker, and Marcel Fafchamps. 2008. "Risk Sharing Relations and Enforcement Mechanisms." CSAE Working Paper 2008-14.

Berg, Joyce, John Dickhaut, and Kevin McCabe. 1995. "Trust, Reciprocity, and Social History." Games and Economic Behavior, 10(1): 122-142.

Bibars, Iman. 2001. Victims and Heroines: Women, Welfare and the Egyptian State. New York:Palgrave.

Bohnet, Iris, and Bruno S Frey. 1999. "Social Distance and Other-Regarding Behavior in Dictator Games: Comment." American Economic Review, 89(1): 335-339.

Bohnet, Iris, Benedikt Herrmann, and Richard Zeckhauser. forthcoming. "The Requirements for Trust in Gulf and Western Countries." Quarterly Journal of Economics.

Brañas Garza, Pablo, Ramón Cobo-Reyes, María Paz Espinosa, Natalia Jiménez, Jaromír Kováík, and Giovanni Ponti. forthcoming. "Altruism and Social Integration." Games and Economic Behavior.

Camerer, Colin. 1988. "Gifts as Economic Signals and Social Symbols." American Journal of Sociology, 94(1988): 180-214. 
Cardenas, Juan Camilo, and Jeffrey Carpenter. 2008. "Behavioural Development Economics: Lessons from Field Labs in the Developing World." Journal of Development Studies, 44(3): 311338.

Castillo, Marco, and Michael R Carter. 2002. "The Economic Impacts of Altruism, Trust and Reciprocity: An Experimental Approach to Social Capital." mimeo.

Charness, Gary, and Martin Dufwenberg. 2006. "Promises and Partnership." Econometrica, 74(6): 1579-1601.

Coate, Stephen, and Martin Ravallion. 1993. "Reciprocity without Commitment: Characterization and Performance of Informal Insurance Arrangements." Journal of Development Economics, 40: 1-24.

Coleman, James. 1990. Foundations of Social Theory. Cambridge:Belknapp Harvard.

Cox, Donald, and Marcel Fafchamps. 2008. "Extended Family and Kinship Networks: Economic Insights and Evolutionary Directions." In Handbook of Development Economics. Vol. 4, , ed. Paul T Schultz and John A Strauss, Chapter 58, 3711-3784. Elsevier.

D'Exelle, Ben, and Arno Riedl. 2008. "Directed Generosity in Social and Economic Networks." mimeo.

Dohmen, Thomas, Armin Falk, David Huffman, Uwe Sunde, Jürgen Schupp, and Gert G Wagner. 2005. "Individual Risk Attitudes: New Evidence from a Large, Representative, Experimentally-validated Survey." IZA Discussion Paper 1730.

Eckel, Catherine C, and Rick K Wilson. 2004. "Is Trust a Risky Decision?" Journal of Economic Behavior and Organization, 55(4): 447-465.

Ermisch, John, and Diego Gambetta. 2008. "Do Strong Family Ties Inhibit Trust?" ISER Working Paper 2008-37.

Fafchamps, Marcel. 1992. "Solidarity Networks in Preindustrial Societies: Rational Peasants with a Moral Economy." Economic Development and Cultural Change, 41(1): 147-174.

Fafchamps, Marcel. 1996. "The Enforcement of Commercial Contracts in Ghana." World Development, 24(3): 427-448. 
Fafchamps, Marcel. 1999. Rural Poverty, Risk, and Development. Food and Agriculture Organization.

Fehr, Ernst. 2009. "On The Economics and Biology of Trust." Journal of the European Economic Association, 7(2-3): 235-266.

Foster, Andrew D, and Mark R Rosenzweig. 2001. "Imperfect Commitment, Altruism, and the Family: Evidence from Transfer Behavior in Low-Income Rural Areas." Review of Economics and Statistics, 83(3): 389-407.

Fukuyama, Francis. 1996. Trust: The Social Virtues and The Creation of Prosperity. New York:Free Press.

Glaeser, Edward L, David I Laibson, Jose A Scheinkman, and Christine L Soutter. 2000. "Measuring Trust." Quarterly Journal of Economics, 115(3): 811-846.

Goeree, Jacob K, Margaret A Mcconnell, Tiffany Mitchell, Tracey Tromp, and Leeat Yariv. 2010. "The 1/d Law of Giving." American Economic Journal: Microeconomics, 2(1): 183203.

Greif, Avner. 1994. "Cultural Beliefs and the Organization of Society: A Historical and Theoretical Reflection on Collectivist and Individualist Societies." Journal of Political Economy, 102(5): 912-950.

Hardeweg, Bernd, Lukas Menkhoff, and Hermann Waibel. 2009. "Experimentally-validated Survey Evidence on Individual Risk Attitudes in Rural Thailand." mimeo.

Hoffman, Elizabeth, Kevin McCabe, and Vernon L Smith. 1996. "Social Distance and Other-Regarding Behavior in Dictator Games." American Economic Review, 86(3): 653-660.

Hoffman, Elizabeth, Kevin McCabe, and Vernon L Smith. 1999. "Social Distance and Other-Regarding Behavior in Dictator Games: Reply." American Economic Review, 89(1): 340341.

Homans, George C. 1950. The Human Group. New York:Harpers.

Hoodfar, Homa. 1997. Between Marriage and the Market - Intimate Politics and Survival in Cairo. Berkeley, CA:University of California Press. 
Houser, Daniel, Daniel Schunk, and Joachim Winter. forthcoming. "Distinguishing Trust from Risk: An Anatomy of the Investment Game." Journal of Economic Behavior and Organization.

Jackson, Matthew O. 2008. Social and Economic Networks. Princeton:Princeton University Press.

Karlan, Dean S. 2005. "Using Experimental Economics to Measure Social Capital and Predict Financial Decisions." American Economic Review, 95(5): 1688-1699.

Karlan, Dean S, Markus M Möbius, Tanya Rosenblat, and Adam Szeidl. 2009. "Trust and Social Collateral." Quarterly Journal of Economics, 124(3): 1307-1361.

Kranton, Rachel E. 1996. "Reciprocal Exchange: A Self-Sustaining System." American Economic Review, 86(4): 830-851.

Kreps, David M, Paul Milgrom, John Roberts, and Robert Wilson. 1982. "Rational Cooperation in the Finitely Repeated Prisoners' Dilemma." Journal of Economic Theory, 27: 245-252.

Leider, Stephen, Markus M Möbius, Tanya Rosenblat, and Quoc-Anh Do. 2009. "Directed Altruism and Enforced Reciprocity in Social Networks." Quarterly Journal of Economics, 124(4): 1815-1851.

Leider, Stephen, Markus M Möbius, Tanya Rosenblat, and Quoc-Anh Do. 2010. "What Do We Expect from Our Friends?" Journal of the European Economic Association, 8(1): 120-138.

Marmaros, David, and Bruce Sacerdote. 2006. "How Do Friendships Form?" Quarterly Journal of Economics, 121(1): 79-119.

Miller, Douglas L, A Colin Cameron, and Jonah B Gelbach. 2009. "Robust Inference with Multi-way Clustering." UCDavis Department of Economics Working Paper 09-9.

Morduch, Jonathan. 1999. "The Microfinance Promise." Journal of Economic Literature, 37(4): 1569-1614.

Naef, Michael, Ernst Fehr, Urs Fischbacher, Jürgen Schupp, and Gert G Wagner. 2009. "Decomposing Trust: Explaining National and Ethnical Trust Differences." mimeo. 
Platteau, Jean-Philippe. 1994. "Behind the Market Stage Where Real Societies Exist - Part II: The Role of Moral Norms." Journal of Development Studies, 30(4): 753-817.

Sahlins, Marshall. 1972. Stone Age Economics. New York:Aldine de Gruyter.

Schechter, Laura. 2007. "Traditional Trust Measurement and the Risk Confound: An Experiment in Rural Paraguay." Journal of Economic Behavior and Organization, 62(2): 272-292.

Singerman, Diana. 1995. Avenues of Participation: Family, Politics, and Networks in Urban Quarters of Cairo. Princeton:Princeton University Press.

UNDP. 2005. "Egypt Human Development Report 2005." Institute of National Planning and UNDP, Cairo.

UN-HABITAT. 2003. "The Challenge of Slums: Global Report on Human Settlements 2003." UN-HABITAT, United Nations Human Settlements Programme.

Yamagishi, Toshio, and M Yamagishi. 1994. "Trust and Commitment in the United States and Japan." Motivation and Emotion, 18: 129-66. 


\section{SFB 649 Discussion Paper Series 2010}

For a complete list of Discussion Papers published by the SFB 649, please visit http://sfb649. wiwi.hu-berlin. de.

001 "Volatility Investing with Variance Swaps" by Wolfgang Karl Härdle and Elena Silyakova, January 2010.

002 "Partial Linear Quantile Regression and Bootstrap Confidence Bands" by Wolfgang Karl Härdle, Ya'acov Ritov and Song Song, January 2010.

003 "Uniform confidence bands for pricing kernels" by Wolfgang Karl Härdle, Yarema Okhrin and Weining Wang, January 2010.

004 "Bayesian Inference in a Stochastic Volatility Nelson-Siegel Model" by Nikolaus Hautsch and Fuyu Yang, January 2010.

005 "The Impact of Macroeconomic News on Quote Adjustments, Noise, and Informational Volatility" by Nikolaus Hautsch, Dieter Hess and David Veredas, January 2010.

006 "Bayesian Estimation and Model Selection in the Generalised Stochastic Unit Root Model" by Fuyu Yang and Roberto Leon-Gonzalez, January 2010.

007 "Two-sided Certification: The market for Rating Agencies" by Erik R. Fasten and Dirk Hofmann, January 2010.

008 "Characterising Equilibrium Selection in Global Games with Strategic Complementarities" by Christian Basteck, Tijmen R. Daniels and Frank Heinemann, January 2010.

009 "Predicting extreme VaR: Nonparametric quantile regression with refinements from extreme value theory" by Julia Schaumburg, February 2010.

010 "On Securitization, Market Completion and Equilibrium Risk Transfer" by Ulrich Horst, Traian A. Pirvu and Gonçalo Dos Reis, February 2010.

011 "Illiquidity and Derivative Valuation" by Ulrich Horst and Felix Naujokat, February 2010.

012 "Dynamic Systems of Social Interactions" by Ulrich Horst, February 2010.

013 "The dynamics of hourly electricity prices" by Wolfgang Karl Härdle and Stefan Trück, February 2010.

014 "Crisis? What Crisis? Currency vs. Banking in the Financial Crisis of 1931" by Albrecht Ritschl and Samad Sarferaz, February 2010.

015 "Estimation of the characteristics of a Lévy process observed at arbitrary frequency" by Johanna Kappusl and Markus Reiß, February 2010.

016 "Honey, I'll Be Working Late Tonight. The Effect of Individual Work Routines on Leisure Time Synchronization of Couples" by Juliane Scheffel, February 2010.

017 "The Impact of ICT Investments on the Relative Demand for HighMedium-, and Low-Skilled Workers: Industry versus Country Analysis" by Dorothee Schneider, February 2010.

018 "Time varying Hierarchical Archimedean Copulae" by Wolfgang Karl Härdle, Ostap Okhrin and Yarema Okhrin, February 2010.

019 "Monetary Transmission Right from the Start: The (Dis)Connection Between the Money Market and the ECB's Main Refinancing Rates" by Puriya Abbassi and Dieter Nautz, March 2010.

020 "Aggregate Hazard Function in Price-Setting: A Bayesian Analysis Using Macro Data" by Fang Yao, March 2010.

021 "Nonparametric Estimation of Risk-Neutral Densities" by Maria Grith, Wolfgang Karl Härdle and Melanie Schienle, March 2010. 


\section{SFB 649 Discussion Paper Series 2010}

For a complete list of Discussion Papers published by the SFB 649, please visit http://sfb649. wiwi.hu-berlin.de.

022 "Fitting high-dimensional Copulae to Data" by Ostap Okhrin, April 2010.

023 "The (In)stability of Money Demand in the Euro Area: Lessons from a Cross-Country Analysis" by Dieter Nautz and Ulrike Rondorf, April 2010.

024 "The optimal industry structure in a vertically related market" by Raffaele Fiocco, April 2010.

025 "Herding of Institutional Traders" by Stephanie Kremer, April 2010.

026 "Non-Gaussian Component Analysis: New Ideas, New Proofs, New Applications" by Vladimir Panov, May 2010.

027 "Liquidity and Capital Requirements and the Probability of Bank Failure" by Philipp Johann König, May 2010.

028 "Social Relationships and Trust" by Christine Binzel and Dietmar Fehr, May 2010. 